\title{
Tafsir Atas Teks Alkitab dalam Kaitannya dengan Toleransi Antarumat Beragama
}

\author{
Hendarto Supatra \\ Fakultas Ilmu Budaya Universitas Diponegoro \\ hendartosupatra53@gmail.com
}

\begin{abstract}
Semansitcs is the study of meaning communicated through language. In the past time semantics was the study of meaning of words and sentences. Aboves sentence level which is known as text was never considered as linguistic semantics' objek of study. Semantics which is a branch of structural linguistics only focused it's attention on phones, morphemes, words, clauses, and sentences: substansive matters of language. Texts belong to speech or language system in use. The study of meaning in this area is called pragmatics or discourse analysis.Up to this time linguistics or semantics has been used as an instrument in interpreting the Holy Texts of many religions. In that period the Holy Texts interpretation activity was limited only on lexical and grammatical meaning. Today people are aware, that based on the theory of discourse analysis, texts should be considered as parts of discourse. To get the meaning of the texts significantly people must find the context, but this is the problems, that reconstructing the context of the text in its'origin is a never ending works. Since Holy Text interpretation is a kind of activity closed to mission of imposible, this should teaches us to be low hearted and tolerant to others.
\end{abstract}

Key Words: semantics, pragmatics, discourse analysis, Holy Text Interpretation

\section{Intisari}

Semansitcs adalah studi tentang makna yang dikomunikasikan melalui bahasa. Di masa lalu semantik adalah studi tentang makna kata dan kalimat. Diatas tingkat kalimat yang dikenal sebagai teks tidak pernah dianggap sebagai objek studi semantik linguistik. Semantik yang merupakan cabang linguistik struktural hanya memusatkan perhatian pada fona, morfem, kata-kata, klausa, dan kalimat: masalah bahasa yang substansif. Teks menjadi sistem ucapan atau bahasa yang digunakan. Studi tentang makna di bidang ini disebut analisis pragmatik atau wacana. Sampai saat ini linguistik atau semantik telah digunakan sebagai instrumen dalam menafsirkan teks suci banyak agama. Pada periode itu, aktivitas penafsiran kitab suci terbatas hanya pada makna leksikal dan gramatikal. Saat ini orang sadar, bahwa berdasarkan teori analisis wacana, teks harus dianggap sebagai bagian wacana. Untuk mendapatkan makna teks secara signifikan orang harus menemukan konteksnya, tapi inilah masalahnya, bahwa merekonstruksi konteks teks tidak pernah berakhir. Karena penafsiran kitab suci adalah semacam kegiatan yang tertutup untuk misi yang tidak mungkin, ini seharusnya mengajarkan kita untuk rendah hati dan toleran terhadap orang lain.

Kata kunci: semantik, pragmatik, analisis wacana, interpretasi, kitab suci 


\section{Pendahuluan}

Umat beragama, agama resmi di Indonesia, tidak lagi harus susah payah bergelut dengan teks Kitab Suci mereka dalam bahasa aslinya. Umat Kong $\mathrm{Hu} \mathrm{Cu}$ tidak harus membaca Kitab Su Sie dalam bahasa Tionghua, umat Hindu dan Budha juga tidak harus belajar keras lebih dahulu untuk sekurangnya bisa membaca bahasa Sansekerta, umat Kristen bisa membaca Injil dalam bahasa Indonesia maupun bahasa daerah mereka masing-masing, umat Islam umumnya bisa membaca Quran dalam bahasa Arab sedangkan ketika hendak membaca dalam arti menafsir juga telah tersedia terjemahan Kitab Suci tersebut dalam bahasa Indonesia. Mudah-mudahan kita semua menyadari bahwa kegiatan menerjemahkan Kitab Suci dari bahasa aslinya (bahasa kuna) yang berupa kumpulan teks itu merupakan proyek raksasa dan melibatkan banyak ahli (ahli linguistic, filologi, teologi, sejarah, dsb.). Sementara itu perubahan bahasa Indonesia yang relative pesat itu juga mau tidak mau harus diperhitungkan, artinya bahwa penerjemahan itu harus selalu direvisi, untuk setiap kurun waktu tertentu, demi efektivitas dan efisiensi penafsiran.

Di samping persoalan penerjemahan (yang hakikatnya merupakan penafsiran juga) di samping sebenarnya merupakan mission imposible atau setidaknya mendekati status demikian itu, juga hasil terjemahannya pun tidak serta merta mudah dimengerti. Mengapa demikian? Para ahli bahasa memberi tahu kita bahwa tiap-tiap bahasa merupakan cara pandang atau cara merekonstruksi realitas yang masing-masing unik pada dirinya. Tokoh yang sangat berwibawa di bidang ilmu bahasa dan antrophologi yakni Edward Sapir (1949:162) membuat pernyataan yang sangat menentukan arah ilmu bahasa/antropologi, dan khususnya berhubungan dengan penerjemahan/penafsiran yang harus disikapi dengan serius dan hati-hati, sebagai berikut.

Language is a guide to 'social reality'. Though language is not ordinarily thoughtof as of essential interest to the students of social science, it powerfully conditionall our thinking about social problems and processes. Human beings do not live in the objective world alone, nor alone in the world of social activity as ordinaryunderstood, but are very much at the mercy of the particular language which hasbecome the medium of expression for their society.

The fact of the matter is that the 'real world' is to a large extent unconsciouslybuilt up on the language habits of the group. No two languages are eversufficiently similar to be considered as representing the same social 
reality.The world in which different societies live are distinct world, not merelythe same world with different labels attached. berikut.

Sejalan dengan pendapat Sapir yang adalah gurunya, Whorf menulis sebagai

(Language) is not merely a reproducing instrument for voicing ideas butrather is itself the shaper of ideas, the program and guide for the individual'smental activity, for his analysis of impressions, for his synthesis of his mentalstock in trade .... We dissect nature along lines laid down by our native languages. The categories and types that we isolate from the world of phenomenawe do not find there because they stare every observer in the face; on the contrary the world is presented in kaleidoscopic flux of impression which has to be organized by our mind -- and this means largely by the linguistic systems inour minds. We cut nature up, organize it into concepts, and ascribe significancesas we do, largely because we are parties to an agreement to organize it in this way - an agreement that holds throughout our speech community and is codifiedin the patterns of our language (1956:213-14).

Demikianlah agaknya, bahwa memang ada dua macam realitas. Realitas bukan melulu 'ada di luar sana'; realitas itu 'diperantari oleh makna', makna yang masyarakat berikan dalam konteks budaya mereka atau kurun historis mereka yang ditafsir seturut horizon tertentu yang mereka punyai dan dalam bentuk pemikiran mereka yang tertentu pula (Lihat Bevans, 2002). Dalam spirit yang sama Kraft (1979: 300), menulis sebagai berikut.

Selalu ada perbedaan antara realitas dan pemahaman (model) manusia yang secara cultural atas realitas tersebut. Kita mengira bahwa realitas itu 'ada di luar sana', namun konstruk (model) mental tentang realitas -yang ada di dalam kepala kita-itulah yang paling riil bagi kita. Allah, pencipta realitasberada di luar kebudayaan mana pun. Mahluk manusia, di lain pihak, selalu terikat oleh kondisi cultural, subkultural (termasuk disiplin) serta kondisi psikologis untuk mengindrai dan menafsirkan apa yang mereka lihat tentangrealitas seturut cara-cara yang cocok dengan kondisi-kondisi tersebut. BaikAllah yang mutlak maupun realitas yang Allah ciptakan tidak bisa dipahami secara mutlak oleh mahluk manusia yang terikat secara cultural (Dikutip dan diterjemahkan dalam Bevans, 2002:3).

Kraft adalah seorang guru besar di USA dalam linguistic dan antropologi. Dia juga seorang missionary yang lama tinggal di Afrika sehingga dia bukan hanya kaya terori akan tetapi juga kaya pengalaman di lapangan, di antara suku-suku di Afrika.

Menjadi sempurna sudah keterkejutan penulis ketika membaca pernyataan raksasa ahli bahasa lainnya yakni Humboldt sebagai berikut " there are very few words in any language which do have exact equivalents in other languages" (Wierzbicka, 1992:5).Betapa 
sangat tidak sederhana kegiatan menafsir atau menerjemahkan itu. Betapa gegabahnya orang yang mengira dirinya telah memperoleh pengetahuan yang mutlak tingkat kebenarannya sebagai hasil kerja penafsirannya, lebih lagi ketika yang dibaca atau ditafsir itu teks klasik (kuna) yang berjarak ratusan atau malah ribuan tahun yang lalu. Berikut ini contoh-contoh tentang keunikan tiap-tiap bahasa dan tentu saja hal itu menimbulkan kesulitan dalam penerjemahan.

Dalam bahasa Aztect Timur di Amerika Tengah tidak didapatkan kata khusus yang dalam bahasa Indonesia disebut lambung. Bahasa penduduk asli Amerika ini hanya mengenal perbedaan antara rongga dada dan rongga perut. Nah, ketika seorang penerjemah hendak menerjemahkan bahwa Gusti Yesus telah ditombak pada lambungNyaketika Ia ada di kayu salib, penerjemah ini harus menegaskan apakah tombak itu telah menembus titik di bawah tulang iga atau di antara tulang iga (Lihat Nida and Taber, 1969 dalam Wierzbicka, 1992:8). Pada hal dalam teks aslinya tidak digunakan kata tulang iga. Contoh lain yang sudah dikenal secara luas, misalnya perihal bagaimana kita hendak menerjemahkan kata ndeprok, mencep-mencep, kimplah-kimplah, pating grandul, dst. ke dalam bahasa Inggris. Jangankan ke dalam bahasa Inggris ke dalam bahasa Indonesia, yang masih serumpun dengan bahasa Jawa, pun itu sesungguhnya tidak mungkin untuk dilakukan penerjemahan dalam arti dicarikan padanannya dalam bahasa Indonesia. Memang bisa, tidak diterjemahkan tetapi diterangkan akan tetapi dengan cara demikian itu tentu ada yang terhilang.

Suatu ketika saya membuka Kitab Injil pada Matius pasal 5 ayat 3 yang terbaca sebagai berikut: “ Berbahagialah orang yang miskin di hadapan Allah, karena merekalah yang empunya Kerajaan Surga" (Alkitab Terjemahan Baru, 2008). Ayat ini apabila ditafsir secara harafiah dan terlepas dari co-teks maupun konteksnya, makna yang tertangkap adalah bahwa miskin itu dikehendaki Allah, miskin dalam pengertiannya yang paling umum yakni sama dengan 'mlarat'. Bahwa Allah mengasihi orang-orang yang tidak beruntung di dunia ini termasuk kaum papa-dina, tentu memang demikian halnya. Tetapi bahwa Allah menghendaki orang-orang agar miskin dalam pengertian ini supaya bisa masuk Surga, tentu tidak demikian halnya. Lalu bagaimana mengartikan miskin dalam konteks Khotbah di Bukit yang sangat dikenal oleh umat Kristen itu? Untuk ini saya 
mencoba membandingkan teks di atas dengan terjemahan lain, dan saya dapatkan sebagai berikut.

"Blessed are the poor in spirit, for theirs is the kingdom of heaven"(Holy Bible,New International Version, 2008).

" Salamet orang jang miskin hatinja, karna dia-orang ampoenja keradjaan sorga”(Injil, Tersalin kepada Bahasa Melajoe Rendah, 1934).

“ Rahayu wong kang mlarat ing budi, awit iku kang padha nduweni Kraton Ing Swarga" (Kitab Suci, 1981).

" Berbahagialah orang yang merasa tidak berdaya dan hanya bergantung padaTuhan saja; mereka adalah anggota umat Allah" ( Alkitab dalam Bahasa Indonesia Sehari-hari, 1992).

Tanpa bimbingan orang yang terdidik dalam ilmu tafsir jelas orang akan kebingungan menghadapi realitas tafsir/terjemahan di atas: 'miskin di hadapan Allah' berpadanan dengan 'poor in spirit', dengan 'miskin hatinya', dengan 'mlarat ing pambudi', dan dengan 'merasa tak berdaya dan hanya bergantung pada Tuhan saja'. Dengan memburu pengertian miskin di hadapan Allah pada sejumlah buku tafsir (Bandingkan Fee \& Stuart, 1982) barulah diketahui bahwa kata Latin klasik yang diterjemahkan menjadi 'poor in spirit' itu ternyata, “ "...to refer to those reduced to cowering in dark coners of the city street begging for handouts. Because they had no personal resourses, they were totally dependent on the gifts of others" (MacArthur, Jr. 1993: April 3). Nah, tanpa mengetahui konteks social-budaya jaman itu tentu akan sulit untuk mengetahui maksud dari digunakannya kata yang kemudian diterjemahkan, dalam salah satu versi penerjemahan, dalam bahasa Indonesia, yakni miskin di hadapan Allah. Semua terjemahan di atas relative jelas bagi masyarakat penutur bahasa, bahasa yang digunakan untuk menerjemahkan, sedangkan bagi penulis artikel ini, terjemahan dalam bahasa Indonesia sehari-harilah yang paling jelas maksudnya. Oleh karena penulis bukan penutur asli bahasa Inggris atau pun kurang baik penguasaan bahasa Inggrisnya, membaca dan mengartikan 'poor in spirit' untuk pengertian yang demikian tadi itu sungguh tidak mudah. Ya memang benar, beruntunglah manusia sekarang ini sebab di samping ada banyak terjemahan Alkitab yang bisa digunakan sebagai pembanding atau cek dan recek, ada pula buku-buku tafsir, dan ditambah lagi dengan ilmu- 
ilmu bantu seperti linguistic, antropologi, komunikasi dan tentu saja hermeneutic.Perihal ilmu yang disebut terakhir itu akan di singgung lagi pada halaman-halaman berikut.

\section{Masalah Serius Perihal Telaah Teks dan Telaah Wacana}

Telaah teks dan wacana merupakan puncak dari gelombang demi gelombang perkembangan ilmu bahasa. Ilmu bahasa (modern) atau linguistic adalah ilmu yang mengkaji bahasa atau bahasa-bahasa secara ilmiah. Sebagai ilmu, linguistic ini baru dimulai sekitar pertengahan abad XIX. Pada waktu itu yang dimaksud dengan linguistic masih berupa linguistic diakronik dan bercorak historis komparatif yang bertujuan untuk memetakan keserumpunan bahasa-bahasa yang ada serta untuk merekonstruksi proto bahasa dari bahasa-bahasa serumpun tadi. Pada akhir abad XIX atau awal abad XX barulah dimulai penelitian bahasa secara sinkronik yang kemudian dikenal sebagai linguistic sinkronik atau linguistic deskriptif yakni penelitian bahasa pada kurun waktu tertentu, biasanya kurun waktu kini atau saat ini. Ferdinand de Saussure yang kemudian dikenal sebagai bapak linguistic adalah orang yang meletakkan dasar atau pijakan dari ilmu bahasa modern ini.

Awal abad XX hingga tahun 30-an merupakan masa perkembangan fonologi atau cabang linguistic yang mengkaji bunyi bahasa. Dari tahun 30-an hingga tahun 50-an para ahli bahasa mulai merambah ke wilayah morfologi yakni cabang linguistic yang mengkaji seluk-beluk morfem dan perilaku morfem sebagai unsur pembentuk kata. Setakat ini penelitian bahasa masih terkonsentrasikan pada soal bentuk( yang dapat dicerap oleh indra pendengaran atau pun indra penglihatan) dan ketika disinggung perihal makna, pembicaraan tentang makna itu hanya untuk kepentingan pemahaman yang lebih mendalam perihal aspek bentuk tadi. Pada tahun 60-an ketika para ahli mulai memasuki wilayah sintaksis, pembicaraan perihal makna menjadi semakin sulit diabaikan. Sejak waktu itulah semantic mulai menarik perhatian. Akan tetapi pembicaraan perihal makna dalam kerangka linguistic ini masih sebatas makna dalam satuan-satuan atau bentuk-bentuk bahasa sebagai unsur system bahasa. Satuan atau bentuk bahasa yang dianggap merupakan satuan tertinggi adalah kalimat. Jadi dalam tradisi linguistic (structural) ini pembicaraan tentang unsureunsur dan struktur-struktur masih sebatas pembicaraan system bahasa. Unsur-unsur yang 
dimaksud yakni fonem, morfem, kata, frasa, klausa, dan kalimat, disepakati sebagai unsureunsur substansial (bahasa). Ilmu bahasa tidak boleh melewati batas itu.

Pada saat sintaksis mencapai perkembangannya begitu rupa; seluk-beluk kalimat telah diselidiki sedemikian luas dan mendalamnya, para ahli, dalam kewajarannya, mulai tertarik pada bentuk di atas kalimat yakni bentuk-bentuk yang terdiri dari sejumlah kalimat yang merupakan kesatuan. Di sini orang mulai melihat adanya kohesi dan koherensi yang menjamin akan adanya satuan bahasa di atas kalimat. Sejak itu sebagian linguis berpendirian bahwa satuan bahasa yang kemudian disebut teks itu sudah berada di luar wilayah linguistic, sedangkan sebagian yang lain menganggapnya sebagai termasuk ke dalam wilayah kajian linguistik. Persoalannya ialah bahwa setiap teks itu tentu sudah merupakan tuturan atau speech atau 'bahasa dalam pemakaian'. Jadi sudah melampaui system bahasa. Ketika orang masuk ke dalam wilayah bahasa-dalam-pemakaian, maka teks itu bukanlah sesuatu yang utuh atau lengkap pada dirinya; teks hanyalah bagian saja dari wacana. Ada pun wacana atau diskursus atau discourse itu terdiri dari teks dan konteks. Analisis teks mungkin sekali dilakukan tanpa mengingat atau mengikatkan teks itu dengan konteksnya, dan analisis yang demikian itu dianggap termasuk ke dalam ilmu bahasa. Teks di sini diteliti tidak dengan melibatkan konteks. Jadi teks diperlakukan sebagai bentuk di atas kalimat dan masih tergolong ke dalam wilayah substasi bahasa. Kajian teks semacam ini, yang hanya berurusan dengan soal kohesi dan koherensi, menjadi semacam persoalan tata bahasa pada tataran di atas kalimat, dan dikenal sebagai kajian teks dalam tradisi linguistic yang oleh AS Hikam dimasukkan ke dalam kelompok positivism-empiris (Lihat Eriyanto, 2012: 4).

Bagi pengikut aliran ini, bahasa dilihat semata-mata sebagai sarana yang menghubungkan manusia dengan realitas di luar dirinya. Setakat ini orang mengira bahwa pengalaman-pengalaman hasil pengindraan bisa secara langsung diekspresikan melalui penggunaan bahasa tanpa adanya kendala atau distorsi, sejauh pengekspresian itu mengindahkan kaidah logika dan sintaktis serta benar-benar memiliki hubungan dengan realitas empiris. Dalam hubungannya dengan analisis atau penafsiran teks ialah bahwa orang tidak perlu memperhatikan makna-makna subjektif serta nilai-nilai yang mendasari pernyataannya, sebab yang penting ialah apakah pernyataan atau teks merupakan pernyataan yang benar secara sintaksis dan tentu saja semantic, serta kesatuan teks yang 
ditandai oleh kohesi dan koherensi tadi. Jadi, sekali lagi, dalam aliran ini masalah ketatabahasaan menjadi ukuran utama dalam memahami atau menggali makna teks.

Dikarenakan oleh konsentrasi pada masalah ketatabahasaan ini maka positivism empiris, dalam penafsiran atau upaya pengungkapan makna ini mengabaikan konteks. Padahal, setiap pernyataan, termasuk dalam hal ini, teks-teks Firman Tuhan yang terdapat dalam Ktitab Suci tidak hanya mengadung makna atau arti akan tetapi juga mengandung maksud-maksud tertentu dari subjek pembuat pernyataan. Dalam pemakaian bahasa atau teks dan konteksnya, justru subjek yakni penutur atau penulis merupakan unsure sentral. Setiap tuturan selalu mengandung maksud tertentu, tujuan tertentu. Justru di sinilah, analisis teks atau lebih tepatnya lagi analisis wacana (teks dan konteksnya) dimaksudkan untuk membongkar atau menggali dan mengungkapkan maksud-maksud tersembunyi dari penulis teks. Dari sudut pandang para pakar komunikasi, ilmu yang sedang sangat diminati orang, pada akhirnya baik makna, arti, atau pun maksud suatu tuturan/teks ditentukan oleh masyarakat pembaca atau penerima pesan teks yang pertama (Lihat Kraft, 1983: 111). Padahal masyarakat tutur itu selalu terdiri dari sub-sub masyarakat tutur sehingga persoalannya menjadi lebih tidak sederhana lagi. Tentang hal ini, Kraft menulis sebagai berikut: "... the more impressive fact is that people interprat phenomena and event according to patterns agreed to by the members of the group. And such interpretations differ, sometimes widely, from group to group"(hal. 111).

Setiap submasyarakat tutur itu sebenarnya menyimpan kepentingan-kepentingan dan dideologi tertentu. Padahal tiap-tiap masyarakat itu mempunyai apa yang oleh Van Dijk disebut kognisi social semacam kerangka pikir yang mengarahkan dan membatasi ruang gerak penafsiran. Singkatnya, di samping konteks social-budaya-politik-ekonomi yang sangat menentukan makna dan maksud teks, juga masih harus diperhitungkan dengan serius perihal kognisi social yang juga merupakan konteks, katakanlah konteks - dekat teks yang dibaca/diinterpretasikan. Tentu saja penemuan-penemuan mutakhir perihal factorfaktor yang mesti, tidak bisa tidak, diperhitungkan dalam menafsir teks, lebih-lebih teks kuna, menyadarkan orang untuk selalu rendah hati dan terbuka terhadap perbedaanperbedaan hasil interpretasi. Repotnya lagi, tiap-tiap orang pada saat sekarang ini juga terhisab ke dalam berbagai masyarakat atau submasyarakat yang berbeda-beda. Bukankah sebagaimana telah dikemukakan di depan, bahwa adanya berbagai aliran dalam agama- 
agama maupun ideology yang ada saat ini disebabkan oleh adanya berbagai komunitas dengan latar belakang yang berbeda-beda itu. Sampai di sini inilah orang menyadari betapa pentingnya hermeneutic, ilmu yang memberi petunjuk perihal bagaimana menafsirkan teks sehingga makna dan maksud teks yang kita peroleh saat ini tetap sama atau paling tidak diusahakan mendekati status sama dengan yang dimaksudkan semula (Bandingkan Fee \& Stuart, 1989:xi).

\section{Simpulan}

Beberapa hal yang bisa dimanfaatkan dari uraian di atas, antara lain, yang pertama bahwa perkembangan linguistic atau lebih spesifiknya semantic telah mencerahi kita bahwa teks Firman Tuhan itu tidak berada dalam ruang hampa; teks itu baru memuat makna secara parsial yang keutuhannya baru tercapai ketika berhasil diletakkan dalam konteks masa purba teks tersebut. Yang kedua, sekian lama para penafsir cenderung puas ketika sampai pada perolehan makna tekstual, dikarenakan pada saat itu ilmu bahasa atau linguistic termasuk cabangnya yang disebut semantic masih berkutat pada soal tata bahasa dan belum sampai pada soal komunikasi, bahasa dalam pemakaian. Padahal teks adalah bahasa dalam pemakaian. Yang ketiga, dengan berkembangnya ilmu bahasa, di satu pihak disadari bahwa demi diperolehnya makna dan maksud teks, tidak ada jalan lain kecuali memperhitungkan konteks mula-mula dari teks tersebut, di alin pihak, setidaknya sampai setakat perkembangan ilmu-ilmu social-budaya saat ini, rekonstruksi konteks purba semacam itu di samping rumit bukan main juga memang masih sedikit yang telah dicapai. Yang keempat, agaknya orang per orang atau pun komunitas-komunitas yang ada saat ini dalam realitasnya terkondisi oleh latar belakang mereka masing-masing, maka meski diakui danditerima pula berbagai perbedaan atau variasi interpretasi atas teks Firman Tuhan. Agaknya dalam hal ini pun ajakan untuk menyikapi perbedaan sebagai rahmat Tuhan, berlaku juga.

Akhirnya, mesti diakui, bahwa siapapun yang telah mencapai tingkat kematangan atau kedewasaan berpikir, tidak akan mengingkari realitas di atas. Tentu saja tiap-tiap umat harus tetap berdiri kokoh dan berakar semakin kuat pada keyakinan masing-masing sembari membuka lebar-lebar pintu dan jendela silaturahmi yang produktif, kreatif, menyegarkan dan mencerahkan. Dunia yang disediakan Allah, menyediakan diri untuk terus diubah secara kreatif dan bertanggung jawab. Dan untuk itu berbagai pemikiran dan karya luhur 
yang tentu sejalan dengan nilai-nilai kemanusiaan universal mesti ditebar dan ditumbuhsuburkan di taman peradapan bangsa-bangsa.

\section{Daftar Pustaka}

Bevans, Stephen B. 2002. Model-model Teologi Kontekstual. Maumere: Penerbit Ledalero.

Bussmann, Hadumond. 1996. Dictionary of Language and Linguistics. New York: Routledge.

Chaer, Abdul. 2009. Pengantar Semantik Bahasa Indonesia. Jakarta: PT Rineka Cipta.

Cotterell, Peter \& Turner, Max. 1989. Linguistics and Biblical Interpretation. Illinois: University Press.

Fee, Gordon D. \&Stuart, Douglas. 1989. Hermeneutik, Bagaimana Menafsirkan Firman Tuhan Dengan Tepat. Malang: Penerbit Gunung Mas.

Kraft, Charles H. 1983. Communication Theory for Christian Witness. Nashville: Abingdon Press.

1990. Christianity in Culture, A Study in Dynamic Biblical Theologizing inCross-Cultural Perspective. New York: Orbis Books.

Larson, Mildred L. 1988. Penerjemahan Berdasar Makna: Pedoman untuk Pemadanan Antar-Bahasa. Jakarta: Arcan.

Lobner, Sabastian. 2002. Understanding Semantics. Bodmin, Cornwall: MPG Books Ltd.

Lyons, John. 1977. Semantics. London: Cambridge University Press.

Sapir, Edward.1949. Selected writing of Edward sapir in language, culture and personallity. Ed. David Mandelbaum. Berkeley: University of California Press.

Saeed, John I. 1999. Semantics. Oxford: Blackwell Publisher Ltd.

Silva, Moises. 1983. Biblical Words \& Their Meaning, An Introduction to Lexical Semantics.USA: Academic Books.

Whorf, Banjamin Lee. 1956. Language, Thought, and Reality: Selected writing of Benjamin Lee Whosf. Ed. John B. Carroll. New York: Wiley.

Wierzbicka, Anna. 1992. Semantics, Cultute, and Cognition, Universal Uman Concepts in Culture-Specific Configuration. Oxford: Oxford University Press. 